\title{
Cadmium Doped with Selenides and Telluride for Photovoltaic Applications: A Review
}

\author{
Nivetha $\mathbf{S}^{1,2}$, Perumalsamy $\mathbf{R}^{1,3}$, Ayeshamariam $\mathrm{A}^{1,2 *}$, Srinivasan $\mathbf{M P}^{4}$, Mohamed Saleem $\mathrm{A}^{1,5}$, Punithavelan $\mathbf{N}^{4}$ and Jayachandran $\mathbf{M}^{6}$ \\ ${ }^{1}$ Research and Development Center, Bharathidasan University, Thiruchirappalli, 620 024, India \\ ${ }^{2}$ Department of Physics, Khadir Mohideen College, Adirampattinam, 614 701, India \\ ${ }^{3}$ Department of Physics, Sir Theagaraya Higher Secondary School, Chennai, 600 021, India \\ ${ }^{4}$ Department of Physics Divisions, School of Advanced Sciences (SAS), VIT University Chennai Campus, Chennai, 600 127, India \\ ${ }^{5}$ Department of Physics, Jamal Mohamed College, Thiruchirappalli, 620024 , India \\ ${ }^{6}$ Department of Physics, Sethu Institute of Technology, Pulloor, Kariapatti, 626 115, India
}

\begin{abstract}
Materials are the heart and soul of photovoltaic devices. Based on the nature of materials, photovoltaics (solar cells) have been classified into various types. Based on its classifications many oxide and metallic materials are mainly used for photovoltaic applications. Device structure and nature of materials are very critical for the overall efficiency and performance of photovoltaics. However here in this particular review we will be only converging on the nature of various materials used to develop solar cells and their performances by using the materials of $\mathrm{C}, \mathrm{Cd}$, In doped Selenides and Telluride. Likewise the use of nanomaterials for biosensors based in thin film, particularly carbon based materials and its doping with selenides and telluride have attracted considerable attention due to provide a high surface-volume ratio, faster electron transfer and label-free responses. This review discussed these materials and its efficiencies.
\end{abstract}

Keywords: Cis solar cells; PV industry; Deposition techniques, Chalcogenides compounds

\section{Introduction}

Global warming is causing a rise in sea levels, and this leads to a loss of coastal wetlands, erosion of shorelines, and increased flooding in coastal areas. Local and regional climate shifts can also have severe impacts on ecosystems and agriculture. Solar power produces no greenhouse gases, so it does not contribute to global warming. Energy experts are evaluating the "energy payback" of PV systems-the time it takes a PV system to generate enough zero-emission energy to equal the energy used to produce it. Chalcogenide $\mathrm{CdSxSe}_{1 \mathrm{x}}$ thin films are most promising materials due to the possibility of adjusting and tailoring their electrical properties [1-3]. Microstructure of thin films differs from the structure of the bulk material of similar compositions and can vary depending on the growth conditions. It has also been found that microstructure and the stoichiometry of CdS-Se thin films were extremely sensitive to its element component ratios where selenium does as donor impurities [4]. Thin films of the ternary CdSxSe compositions can be synthesized by different techniques; such as thermal evaporation technique [5], chemical bath deposition (CBD) technique [6], laser ablation technique [7] and chemical spray pyrolysis thin films of the ternary chalcogenide compound of $\mathrm{CdS}_{0.1} \mathrm{Se}_{0.9}$ have been prepared by thermal evaporation where the physical properties were studied as a function of the film thickness [8].

The thermal evaporation process is widely used because it is an accurate method, where the preparative conditions (evaporation rate, film thickness, surface morphology and the structural state) can be controlled. This technique has already been used for preparation of the thin films of semiconducting compounds and alloys including CdS-Se ternary systems.

A comparative study was carried out among the present thin films and similar samples of the previous literature Solar electric systems also known as photovoltaic (PV) systems have very little impact on the environment, making them one of the cleanest power-generating technologies available. While they're operating, PV systems produce no air pollution, hazardous waste, or noise, and they require no transportable fuels. Because of these benefits, PV can play an important role in mitigating environmental problems like these. Groundlevel air pollution has severe health and environmental effects and contributes to visibility problems in scenic areas. Traditional power sources are the largest contributor to this pollution; in contrast, solar power produces no air pollution. By varying Se and Te concentration cadmium chalcogenides indicate that the band gap of $\mathrm{CdSe}_{(1-x)} \mathrm{Te}_{(\mathrm{x})}$ system can be tuned. Variation in band gap reveals the optoelectronic behavior of these window materials. To achieve high efficiency single and multijunction solar cells, controlling the band gap of the absorber layer is required [9]

Here, we demonstrate an effective, low-cost colloidal method to synthesize a red- to near infrared (NIR) absorbing $\mathrm{Cu}$-doped CdSeTe-alloyed sensitizer via a non-injection one pot approach. These $\mathrm{Cu}$-doped $\mathrm{CdSe}_{0.6} \mathrm{Te}_{0.4} \mathrm{NCs}$ are further studied to measure their structural, compositional, and optical properties. XRD and its initio simulation confirmed the formation of CdSeTe with a cubic structure and $\mathrm{Cu}$-doped CdSeTe-alloyed NCs with a hexagonal structure. EDX compositional analysis clearly showed the doping of $\mathrm{Cu}$ in $\mathrm{CdSeTe}$ NCs. For the photovoltaic performance of the synthesized NCs, we have assembled $\mathrm{TiO}_{2}$ and $\mathrm{Cu}$-doped $\mathrm{CdSeTe}$ using the molecular linker 3-MPA. An ex situ fabrication method has been adopted to exchange the ligands with bi-functional ones. Moreover, for further understanding the $\mathrm{Cu}$ dopant effect on the charge transfer in CdSeTe semiconductor $\mathrm{NCs}$, we have performed band engineering characterization using ab

${ }^{*}$ Corresponding author: Ayeshamariam A, Research and Development Center Bharathidasan University, Tiruchirappalli, 620 024, India, Tel: +91 9486738806 ; E-mail: aismma786@gmail.com

Received July 03, 2017; Accepted August 12, 2017; Published August 20, 2017

Citation: Nivetha S, Perumalsamy R, Ayeshamariam A, Srinivasan MP, Mohamed Saleem A, et al. (2017) Cadmium Doped with Selenides and Telluride for Photovoltaic Applications: A Review. Fluid Mech Open Acc 4: 167. doi: 10.4172/2476-2296.1000167

Copyright: $\odot 2017$ Nivetha S, et al. This is an open-access article distributed unde the terms of the Creative Commons Attribution License, which permits unrestricted use, distribution, and reproduction in any medium, provided the original author and source are credited. 
initio calculations. $(0.5 \mathrm{mmol})$ of Te in $1 \mathrm{~mL}$ of TOP and $2 \mathrm{~mL}$ of ODE at $310^{\circ} \mathrm{C}$, respectively, both under Ar with constant stirring followed by cooling to room temperature. After the injection of the Se and $\mathrm{Te}$ solutions, the reaction system was further heated to $260^{\circ} \mathrm{C}$ at a rate of $2^{\circ} \mathrm{C} / \mathrm{min}$ and kept at this temperature for an additional $30 \mathrm{~min}$ With the injection of Se and Te precursors and the increased temperature, the originally yellow solution turned red, and finally black, indicating the growth of NCs. Aliquots were taken out of the reaction mixture at different temperatures and injected into cold chloroform to terminate the growth of the NCs and further used for optical characterization. On reaching desired QD size, the heat supply to the reaction pot was removed, and the resultant QDs washed with 1:1 of hexane and ethanol to extract the solvent and separate the NCs from the byproducts and any unreacted precursors present. This purification process of NCs was repeated three times. The as-prepared $\mathrm{CdSexTe} \mathrm{f}_{(1-\mathrm{x})}$ solution was further purified by centrifugation and decantation with the addition of acetone, and the NCs were finally stored in chloroform.

Instead, the pre-synthesized colloidal QDs can allow good quality QDs with well-defined particle sizes, size distribution and morphologies as well as ideal photoelectrical properties. Meng et al. reported $5.38 \%$ and 5.04\% of PCEs based on aqueous colloidal CuInS2 QDs and coreshell CdSexTe ${ }_{(1-x)} / \mathrm{CdS}$ QDs, respectively $[10,11]$.

\section{Sensitization Solar Cell}

Sensitization solar cell is based on a charge transfer from light excited organic molecules to a semiconductor with a large band gap which is the basis of photography. Organic dye molecules sensitize silver halide crystallites. Whereas in photography the charge transfer occurs only once to form the silver based photographic image. In sensitization solar cells the circuit is closed through an electrolyte, which allows for continuous current. The whole module is $30 \times 30 \mathrm{~cm}^{2}$ in size [12]. $\mathrm{TiO}_{2}$ nanoparticle layer was used here according to the literature in lower temperature [13] shown in Figure 1a and 1b.

\section{Fabricated dye-senstized solar cell}

By using an absorber which is embedded in a transparent pnjunction, the light-induced charge carriers are separated immediately by the built-in field. No diffusion is necessary to reach the space charge region. Because of this the recombination probability in the absorber is reduced dramatically. In the n-/p-type semiconductors we deal with majority charge carriers which can be easily transported. For this effect a thin absorber is necessary. To guarantee sufficient absorption the layer has to be folded to allow multiple passing of the light. The before mentioned transport mechanisms imply only little requirements to the absorber material. The main problem of other cell concepts, long diffusion length of minority carriers which means high electronic quality, can be overcome. So no electronic but optical properties have to be taken into account. Idea by using an absorber which is embedded in a transparent pn-junction the light-induced charge carriers are seperated immediately by the built-in field. No diffusion is necessary to reach the space charge region. Because of this the recombination probability in the absorber is reduced dramatically. In the $\mathrm{n}$-/p-type semiconductors we deal with majority charge carriers which can be easily transported. For this effect a thin absorber is necessary. To guarantee sufficient absorption the layer has to be folded to allow multiple passing of the light shown in Figure 2.

\section{Organic solar cell}

Zinc copper thalocyanine solar cells by thermal evaporation and especially role of these materials which property made them effective $\mathrm{C}_{60}$ thin films. Organic solar cell solution process, on functionalized $\mathrm{C}_{60}$ and other layers hole and electron transport layers. Three types of organic solar cells are currently developed, molecular organic solar cells made from relatively small organic molecules, Polymer (or Plastic) organic solar cells mainly based on electrically conductive polymers, and sensitization solar cells. Highly porous $\mathrm{TiO}_{2}$ electrodes in a sol-gel process gives the high light to current conversion efficiency. The sensitized photoelectron chemical solar cell based on organic dye sensitized titanium oxide sintered from small particles onto transparent conductive oxide (TCO) glasses is assumed to be very promising because the production costs are expected to be low become the large scale commercial application of photo electrochemical solar energy conversion [13]. But new scientific results were reported on the possible utilization of energy transfer to improve sensitization processes from the Dutch organic solar cells, i.e photosynthesis excitation energy should be transported through organic molecules towards a kind of "reaction center" where in the classical photovoltaic process it is finally used for charge generation, separation and transport shown in Figure 3.
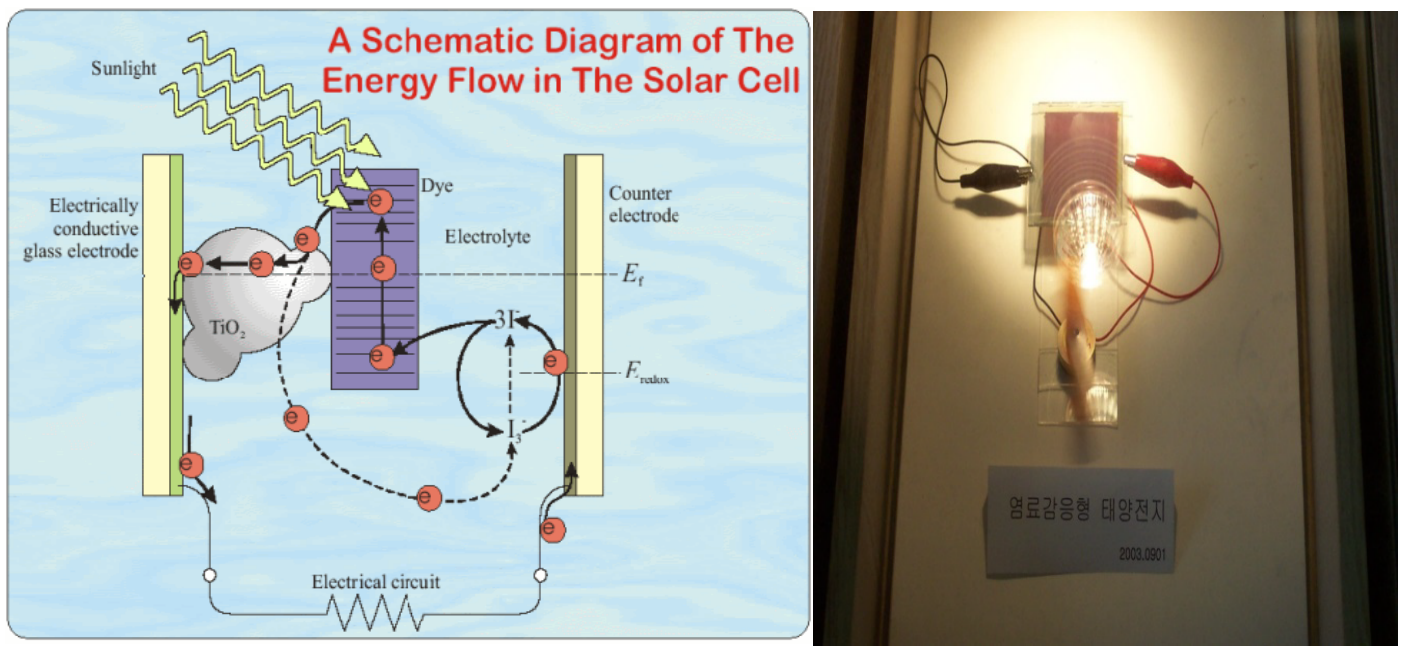

Figure 1: $(a$ and $b)$ Dye sensitized solar cell and its energy flow. A: are of cell; $\quad$ W: cell thickness $\eta$ : efficiency; $V_{o c}$ : open-circuit voltage; $I_{s c}$ : short-circuit current. 


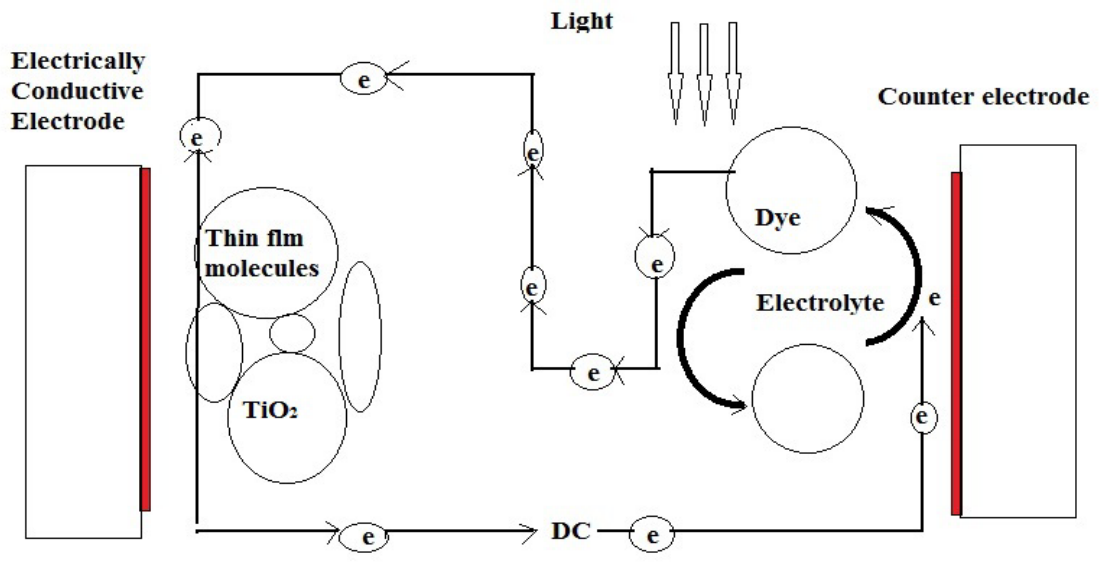

Figure 2: Dye sensitised solar cell for $\mathrm{TiO}_{2}$ thin film.

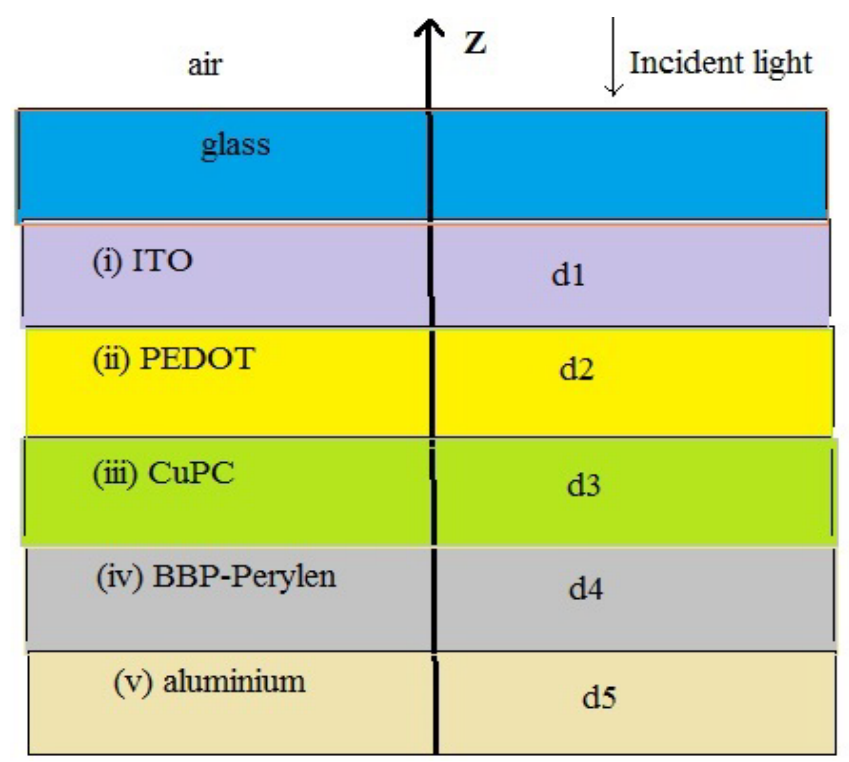

Figure 3: Schematic diagram of Setup of organic solar cell.

\section{Polymer organic solar cells}

Within a very short time, efficiencies in the same order of magnitude as that of molecular organic solar cells were achieved for their plastic solar cells. Based on an extremely fast excited electron transfer from light absorbing semiconducting polymers such as phenylenevinylenes to embedded Fullerene $\left(\mathrm{C}_{60}\right)$ molecules, surprisingly high photocurrents are produced taking into account the relatively low absorption coefficients of most polymers. Depending on the thickness and optical constants of the individual layers, the interaction of a light source with a multilayer causes distict distributions of the electric field and energy absorption density [14]. Studies of electric field distribution in bilayer organic photovoltaic devices made of Zinc-Phthalocyanine (ZnPC), Perylene pigment (MPP) and other materials have been carried out [15]. If the polymer or PCBM domains get too big (as in the case of $80 \mathrm{wt} \%$ PCBM content), the exciton ionization efficiency is not optimal and if the domains are too small, the charge-transfer states will not separate and/or the charge transport to the electrodes is inhibited. Unfortunately, this is made challenging by the fact that charge-transfer states and free charges both show broad and unstructured photo induced absorption in amorphous polymers. P3HT:PCBM blends, however, are a fortunate case, because the absorption of charges in the polycrystalline P3HT changes significantly depending on their confinement. The spectral signature of a charge localized on a single P3HT chain is very different to that of a charge delocalized over several P3HT chains in a crystalline domain. This signature can be used to detect spatially separated charge carriers that have migrated away from the interface into a crystalline polymer region [16-20]. Astuti et al., 130, 10, 3030-3042. Copyright (2008) American Chemical Society reported, the rates of charge-transfer state separation and germinate and nongerminate recombination of charges have been examined using transient absorption spectroscopy on nanosecond to microsecond timescales in PCBM: polythiophene blends [18]. Hwang et al. report a much faster charge separation time (picoseconds) [17]. Despite this discrepancy, it is agreed that the rates vary with material system and morphology, and have been shown to limit the efficiency of organic solar cells $[19,20]$. The pathways available for charge-transfer state recombination vary. In low open-circuit voltage blends, such as those that employ PCBM as an electron acceptor, the charge-transfer states can only recombine directly into the ground state. The absence of any other recombination channels, coupled with the fast kinetics of charge separation due to high carrier mobilities, may explain the high quantum efficiency observed in P3HT:PCBM solar cells. In high open-circuit voltage solar cells, further recombination mechanisms arise, because the triplet exciton on the lower-band-gap polymer are now thermodynamically available. Thus, charge-transfer states can recombine to form a triplet exciton and this also is the fundamental loss channel that reduces the solar-cell quantum efficiency $[21,22]$ shown in Figures 4 and 5.

\section{CIS Solar Cells}

\section{The cds/cdte solar cell}

The cell is produced from polycrystalline materials and glass, which is a potentially much cheaper construction than bulk silicon. The chemical and physical properties of the semiconductors are such that the polysilicon thin-films can be deposited using a variety of different techniques. CdTe has a bandgap which is very close to the theoreticallycalculated optimum value for solar cells under unconcentrated AM1.5 sunlight. CdTe has a high absorption coefficient, so that approximately $99 \%$ of the incident light is absorbed by a layer thickness of only $1 \mu \mathrm{m}$ (compared with around $10 \mu \mathrm{m}$ for $\mathrm{Si}$ ), cutting down the quantity of semiconductor required shown in Figures $6 \mathrm{a}$ and $6 \mathrm{~b}$. 
Citation: Nivetha S, Perumalsamy R, Ayeshamariam A, Srinivasan MP, Mohamed Saleem A, et al. (2017) Cadmium Doped with Selenides and Telluride for Photovoltaic Applications: A Review. Fluid Mech Open Acc 4: 167. doi: 10.4172/2476-2296.1000167

Page 4 of 7

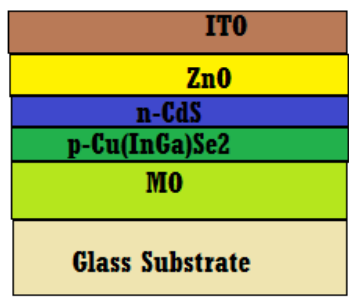

\begin{tabular}{|c|}
\hline Glass Substrate \\
\hline ITO \\
\hline Sn $0_{2}$ \\
\hline -CdS \\
\hline p-CdTe \\
\hline Ni-Al metal contact \\
\hline
\end{tabular}

Figure 4: Schematic diagram of Trilayer structure of $\mathrm{p}-\mathrm{Cu}(\operatorname{lnGa}) \mathrm{Se}_{2}$.

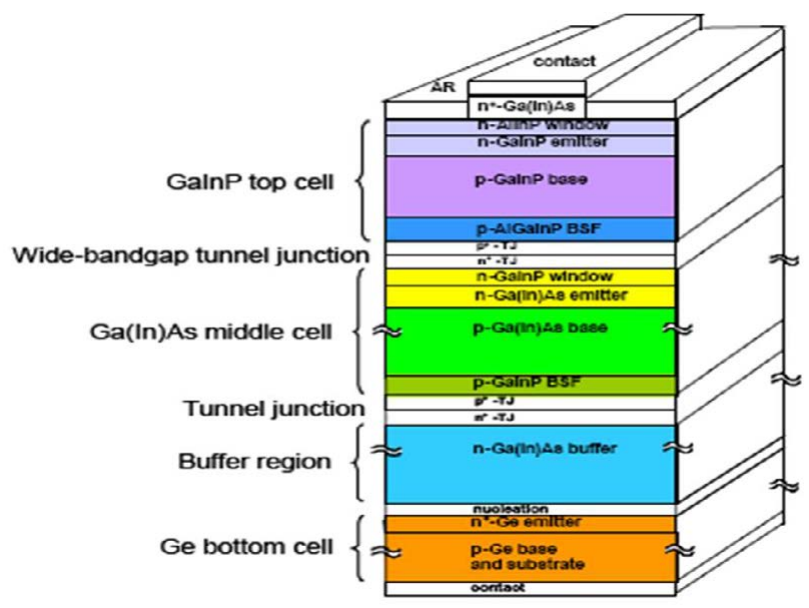

Figure 5: Schematic diagram of GalnP/GaAs cells on Ge triple junction.

\section{hv}

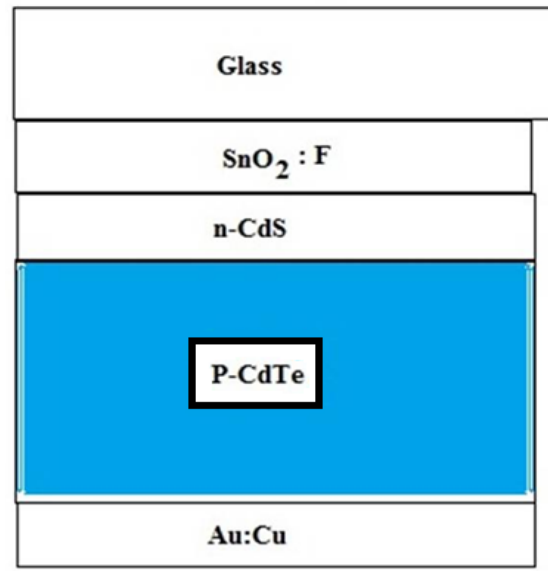

Back ohmic contact

Figure 6a: Schematic diagram of a proposed CdTe solar cell structure.

It has efficiency $27 \%$ under AMO illumination at $28^{\circ} \mathrm{C}, \mathrm{GaInP} /$ GaInAs/Ge by Spectrolab (A Boeing Company) achieved $40.7 \%$ efficiency in 2007. Current devices employed on satellites have efficiencies $\sim 28.3 \%$.CIS has direct band gap with $\mathrm{E}_{\mathrm{g}} 1 \mathrm{eV}$ and high cell efficiency of $19.2 \%$, current complicated and capital intensive fabrication. CdTe has direct band gap of $\mathrm{E}_{\mathrm{g}} 1.45 \mathrm{eV}$ and its efficiency is $16.5 \%$. It has efficiency $27 \%$ under $\mathrm{AMO}$ illumination at $28^{\circ} \mathrm{C}$, GaInP/GaInAs/Ge by Spectrolab (A Boeing Company) achieved $40.7 \%$ efficiency in 2007. Current devices employed on satellites have efficiencies $\sim 28.3 \%$

Glass/SnO $: \mathrm{F} / \mathrm{CdS} / \mathrm{CdTe} / \mathrm{Au}: \mathrm{Cu}$ solar cell structure consists of five layers to fabricate by using the optimized deposition conditions of CdS and CdTe by Electrodeposition. Depositions were carried out for two different optimized Te ion concentrations (40 ppm and 120 $\mathrm{ppm}$ ) and for different deposition potentials from $100 \mathrm{mV}$ to $-700 \mathrm{mV}$. After the deposition of CdTe films on $\mathrm{CdS} / \mathrm{SnO}_{2}: \mathrm{F} /$ glass substrates, the films were dried by nitrogen gas flow and annealed at $200^{\circ} \mathrm{C}$ for 10 minutes to make conversion from n-type to $\mathrm{p}$-type as presented by (Bosal et al. 1984). After the heat treatment the CdTe surface was etched by saturated potassium dichromate in sulfuric acid solution for 2 seconds to remove the Cadmium oxide layers and washed thoroughly with deionised water. Then the samples were dried and dripped into the hydrogen hydrate solution for 15 to 30 minutes and dried in $\mathrm{N}_{2}$ gas flow to mask cadmium deficient surface for the deposition of better ohmic contact with low contact resistance on p-CdTe film. Finally the total structure was transferred to Vacuum chamber and $5000 \AA$ thick $\mathrm{Au}-\mathrm{Cu}$ alloy was deposited for the purpose of back ohmic contact.

CdS films can be successfully deposited on the surface of CdTe NRs by these two different methods. Compared to SILAR method, a high loading and full coverage of CdS film can be obtained by a simple CBD method in a short period of time on CdTe NRs. CdS sensitized CdTe films show significant enhancement in the photoelectric activity compared with bare CdTe films. Through comparing these two methods, it can be observed that the photocurrent density of $\mathrm{CdTe} /$ CBD-CdS films is slightly improved in contrast with CdTe/SILAR-CdS films. According to the excellent optical performance achievement, $\mathrm{CdTe} / \mathrm{CBD}-\mathrm{CdS}$ films can be a promising application in photovoltaic devices.

\section{Fabrication of glass $/ \mathrm{SnO}_{2}: \mathrm{F} / \mathrm{Cds} / \mathrm{CuInSe}_{2} / \mathrm{Ag}$ structure}

Electrodeposited CdS on $\mathrm{SnO}_{2}: \mathrm{F} /$ glass was used as a substrate for the Electrodeposition of $\mathrm{CuInSe}_{2}$ thin films using the solution having $10 \mathrm{mM} \mathrm{CuSO}_{4}, 50 \mathrm{mM} \mathrm{InCl}_{3}$ and $30 \mathrm{mM} \mathrm{SeO}_{2}$ by applying the cathodic deposition potential of -0.4 to $-0.6 \mathrm{~V}$ at $90^{\circ} \mathrm{C}$. After depositing $\mathrm{CuInSe}{ }_{2}$, the films were washed with de-ionised water and dried by nitrogen gas flow. Then the films were transferred to the vacuum chamber for the Ag back ohmic contact deposition of $5000 \mathrm{~A}^{\circ}$ thickness. The fabricated glass $/ \mathrm{SnO}_{2}: \mathrm{F} / \mathrm{CdS} / \mathrm{CuInSe} \mathrm{C}_{2} / \mathrm{Ag}$ structures were annealed in nitrogen atmosphere for 30 minutes at $350^{\circ} \mathrm{C}$ illuminated condition of $100 \mathrm{~mW} /$ $\mathrm{cm}^{2}$ shown in Figures $7 \mathrm{a}$ and $7 \mathrm{~b}$.

\section{Fabrication of Cds/InP/Ag:Zn structure}

LEC (Liquid Encapsulated Czochralski) grown p-type InP (111) single crystals were used as substrates for this cell. The wafers were chemo mechanically polished using $1 \%$ bromine-methanol standard solution. The polished wafers were cleaned first by rinsing in warm trichloroethylene (TCE) acetne and methanol followed by the final etching in $\mathrm{HF}: \mathrm{H}_{2} \mathrm{O}$ (1:1). Alloyed Ag: $\mathrm{Zn}$ material was evaporated on the backside of the cleaned InP substrates for the back ohmic contacts and annealed at $370^{\circ} \mathrm{C}$ for 3 minutes. After masking the back ohmic contacts of InP substrate, the sample was mounted on the cathode for 
Citation: Nivetha S, Perumalsamy R, Ayeshamariam A, Srinivasan MP, Mohamed Saleem A, et al. (2017) Cadmium Doped with Selenides and Telluride for Photovoltaic Applications: A Review. Fluid Mech Open Acc 4: 167. doi: 10.4172/2476-2296.1000167

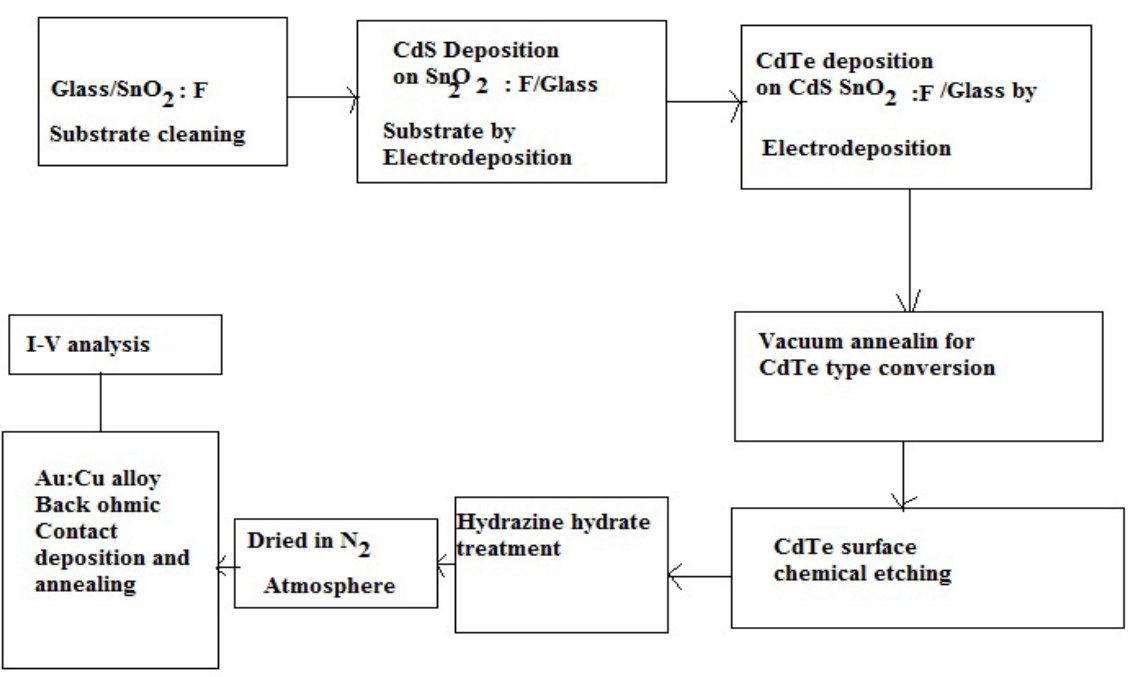

Figure 6b: Block diagram of the adopted fabrication process sequence for CdS/CdTe solar cell.

hv

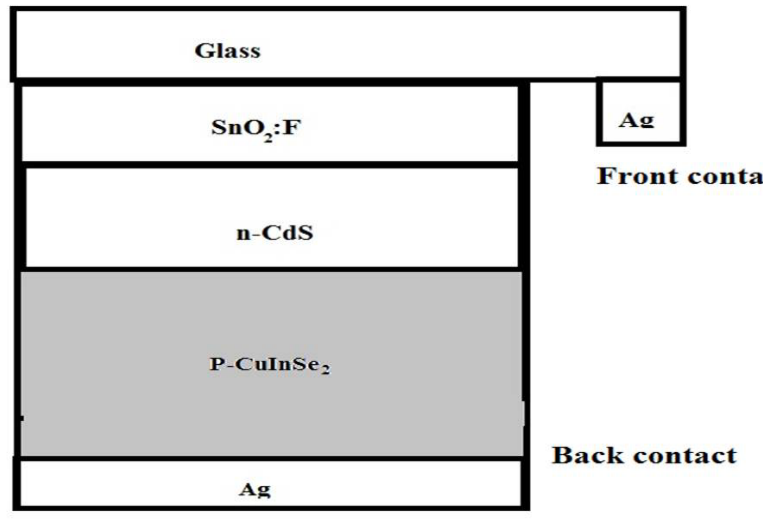

Figure 7a: Schematic diagram of a CdS/CulnSe ${ }_{2}$ solar cell.

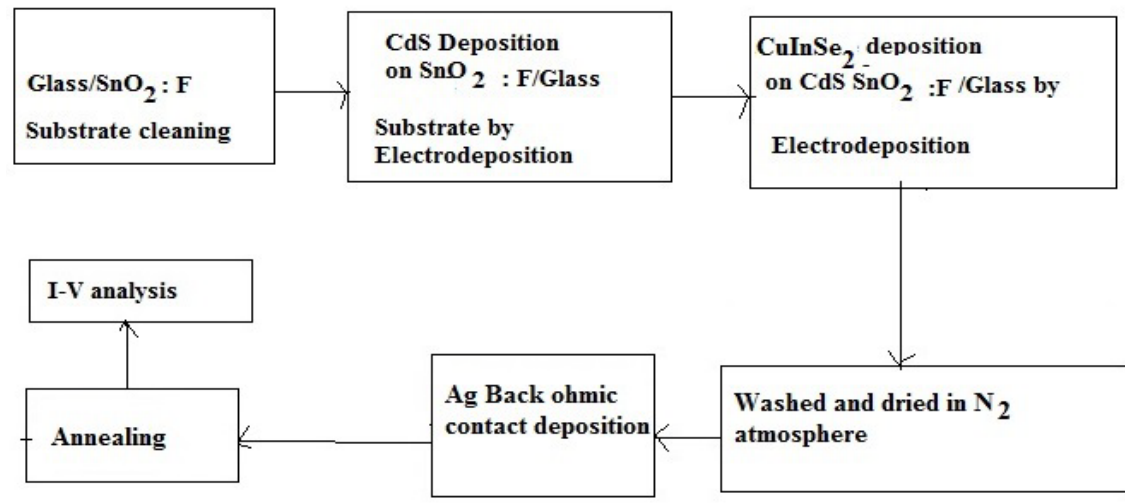

Figure $7 \mathrm{~b}$ : Block diagram of the adopted fabrication process sequence for $\mathrm{CdS} / \mathrm{CulnSe}{ }_{2}$ solar cell. 
CdS deposition on the front side. The optimized deposition condition using $-600 \mathrm{mV}$ as deposition potential was used to deposit CdS thin films on InP (111) substrates. After the deposition, top contact was realized by vacuum evaporated indium fingers. The fabricated cell structure was annealed at $550^{\circ} \mathrm{C}$ under hydrogen atmosphere for 5 minutes before studying the I-V characteristics of the cell structure under $100 \mathrm{~mW} / \mathrm{cm}^{2}$ illuminations. The fabrication process adopted for CdS/p-InP/Ag:Zn solar cell structure is shown in Figures 8a and 8b.

The CBD method produced non-uniformly distributed $\mathrm{CuBiS}_{2}$ nanoparticles - more on the top and less at the bottom of the $\mathrm{TiO}_{2}$ electrode. Consequently, the top surface of the electrode was overloaded, which blocked the flow of the liquid electrolyte, resulting in lower photovoltaic performance. This is probably an intrinsic disadvantage of the CBD method. The Voc $(0.25-0.29 \mathrm{~V})$ obtained here is only moderate. The theoretical upper limit of $\mathrm{Voc}=\mathrm{EF}-\mathrm{E}_{\text {redox }}$, where $\mathrm{EF}$ is the quasi-Fermi level of $\mathrm{TiO}_{2}$ and $\mathrm{E}_{\mathrm{redox}}$ is the redox potential of the electrolyte. It should be possible to increase Voc by using an electrolyte with a lower redox potential (such as cobalt electrolyte).

The deposition of CdSe, ZnSe and Telluride thin films were made using different deposition methods such as, thermal evaporation, pulsed laser deposition (PLD), electrodeposition, spray pyrolysis, successive ionic layer adsorption and reaction (SILAR) and chemical bath deposition (CBD). Among these methods, EBE is one of the most promising methods for making high quality thin films for photovoltaic applications because it is an efficient and reasonably cost effective method.

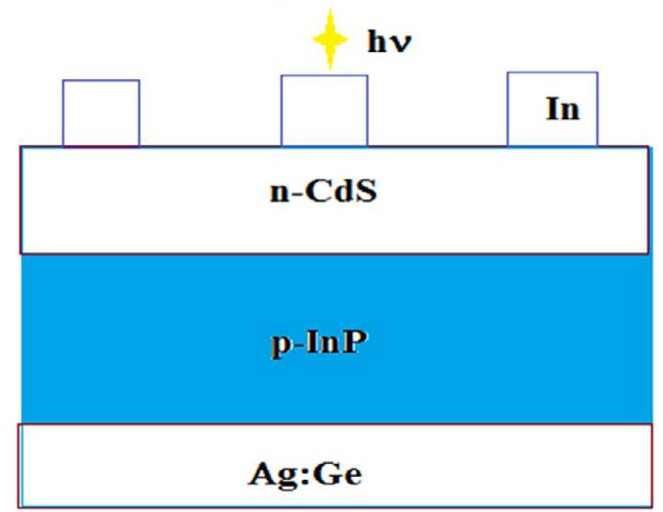

Figure 8a: Schematic diagram of CdS/InP fabricated solar cell structure.

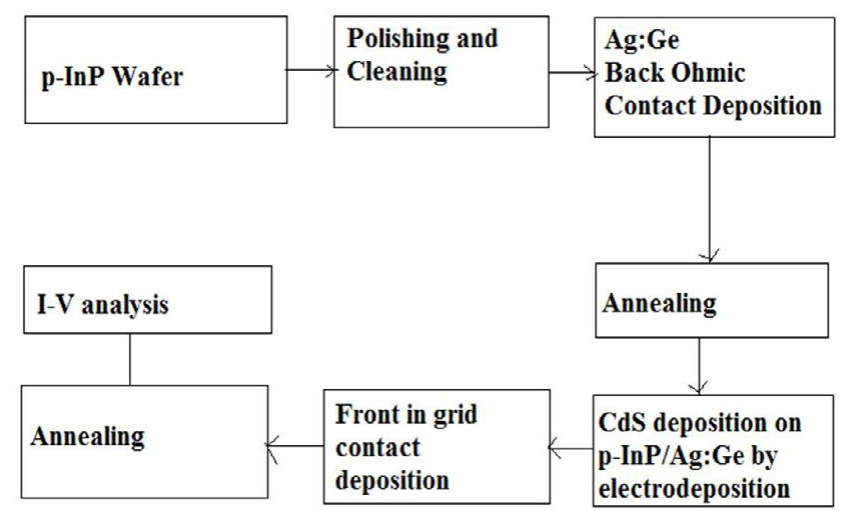

Figure 8b: Block diagram of $\mathrm{CdS} / \mathrm{InP}$ fabricated solar cell structure.
Zinc selenide (ZnSe) has attracted much attention of research and development due to its suitability as a material for the fabrication of blue green lasers. It is seen that the optoelectronic and other properties of $\mathrm{ZnSe}$ thin films are structure sensitive which will severely influence the device performance. The lattice constant of $\mathrm{ZnSe}$ is $0.5668 \mathrm{~nm}$ and $\mathrm{GaAs}$ is $0.5653 \mathrm{~nm}$. Though their lattice constants are nearly the same, $\mathrm{ZnSe}$ is very soft and facilitates the introduction of defects easily with in the film. It is well known that for II-VI compounds wurtzite phase is the stable form of crystal structure and the zinc blende structure is metastable [22].

The gradients of zinc phthalocyanine/C60 were prepared by coevaporation of the two materials from two sources to make a linear array of photodiode devices. $\mathrm{ZnPc}$ has a strong absorption in the mid- visible range, and photoinduced charge transfer between $\mathrm{ZnPc}$ and C60. It is also well as the substrate temperature, can significantly change the photovoltaic properties of the devices. ZnPc in C60 is easily done by co-evaporation of both molecules onto a surface from two separate sources at a distance; a gradient will be formed along the space extending in between the two evaporation sources. These structures are then used for evaluation of solar cell performance [23].

Polymer solar cells are becoming increasingly attractive because they show many potential advantages over traditional silicon-based solar cells. As an energy conservation device, efficiency is a very important parameter. Inorder to increase the PCE (Power Conversion Efficiency) of devices, some aspects should be taken into account, such as the absorption coefficients of the materials, the exciton dissociation rate, and the charge-carrier mobilities. Polymers with bandgaps above $2 \mathrm{eV}$ only absorb radiation in the ultraviolet (UV) and green part of the visible range. [24].

Conjugated polymers blended with soluble fullerene derivatives show a great potential for low cost, large area photovoltaics. One of the most promising devices following this approach are based on poly [2,6-(4,4-bis-(2-ethylhexyl)-4H-cyclopenta[2,1-b;3,4-b0] dithiophene)-alt-4,7-(2,1,3-benzothiadiazole)] (PCPDTBT), reaching power conversion efficiencies of up to $3.2 \%$ when combined with [6,6]-phenyl-C71-butyric acid methyl ester (PC70BM) [25].

Solar-energy generation, especially that of photovoltaics, has great potential as a renewable energy source because of its limitless and non-polluting properties. Recently, several research groups have reported that $\mathrm{BHJ}$ solar cells based on a composite film using poly(3hexylthiophene) (P3HT) as an electron donor and [6,6]-phenylC61-butyric acid methyl ester (PCBM) as an electron acceptor show a power-conversion efficiency near $5 \%$, which is the best reported performance for solution-processed polymer solar cells [26]. In general, the performance of $\mathrm{BHJ}$ solar cells can be maximized by controlling the morphology of the active layer, because efficient photoinduced charge generation, transport, and collection at each electrode crucially depend on the nanometer-scale morphology of the composite films $[27,28]$.

Polymer electrolytes have reasonable ionic conductivities and eliminate the problems of sealing and solvent leakage. Dyesensitized solar cells based on nanocrystalline $\mathrm{TiO}_{2}$ electrodes are currently attracting widespread attention as a low cost alternative to conventional inorganic photovoltaic devices. Efficient light absorption for a monolayer of adsorbed sensitizer dye is achieved by the use of a mesoporous $\mathrm{TiO}_{2}$ film structure $[29,30]$ shown in Table 1 . 
Citation: Nivetha S, Perumalsamy R, Ayeshamariam A, Srinivasan MP, Mohamed Saleem A, et al. (2017) Cadmium Doped with Selenides and Telluride for Photovoltaic Applications: A Review. Fluid Mech Open Acc 4: 167. doi: 10.4172/2476-2296.1000167

\begin{tabular}{|c|c|c|c|}
\hline Samples & FF & PCE (\%) & Reference \\
\hline PTB7 & 42 & $2.46(2.34)$ & [26] \\
\hline PTB7-DCB & 47 & $4.22(3.92)$ & \\
PTB7-Th & 37 & $4.11(3.91)$ & \\
\cline { 1 - 3 } PTB7-Th-DCB & 49 & $6.07(5.60)$ & \\
\hline
\end{tabular}

Table 1: The FF, Efficiency of Polymer materials.

\section{Conclusion}

While the increasing demand for energy creates a boom of PV industry in global market, its widespread use is still hindered by its high costs. A critical requirement is the accessibility of an easily scalable deposition processes for the active layers in order to reduce process complexity and cost of solar. Two stage process has been optimized for producing single phase p-type $\mathrm{CuInSe}, \mathrm{CuIn}\left(\mathrm{Se}_{1-x} \mathrm{~S}_{\mathrm{x}}\right)_{2}$ and n-type $\mathrm{In}_{2} \mathrm{Se}_{3}$ thin films. The material quality of the absorber films is critically related to the chalcogenisation parameters and the metallic precursor formation steps. This review quantifies the influence of the above referred parameters on the material quality of the semiconductor thin films.

\section{References}

1. Wöhrle D, Meissner D (1991) "Organic solar cells." Advanced Materials 3: 129-138.

2. Wojciechowski K, Saliba M, Leijtens T, Abate A, Snaith HJ (2014) Sub$150^{\circ} \mathrm{C}$ Processed meso-superstructured perovskite solar cells with enhanced efficiency. Energy Environ Sci 7: 1142-1147.

3. Chuang PY, Chuang CN, Yu CC, Wang LY, Hsieh KH (2016) Enhance the stability and efficiency of perovskite solar cell via geltype Polyurethane. Polymer 97: 196-204.

4. Peng Z Adam, Xiaogang Peng (2001) "Formation of high-quality CdTe, CdSe, and CdS nanocrystals using $\mathrm{CdO}$ as precursor." Journal of the American Chemical Society 123: 183-184.

5. Patel KD, Jani MS, Parthak VM, Srivastava R (2009) Deposition of CdSe thin films by thermal evaporation and their structural and optical properties. Chalcogenides Letters 6: 279-286

6. Brien O, McAleese $\mathrm{J}$ (1998) "Developing an understanding of the processes controlling the chemical bath deposition of $\mathrm{ZnS}$ and CdS." J Mater Chem 8: 2309-2314.

7. Perna G, Capozzi V, Minafra A, Pallara M, Ambrico M (2003) "Effects of the indium doping on structural and optical properties of CdSe thin films deposited by laser ablation technique." The European Physical Journal B-Condensed Matter and Complex Systems 32: 339-344.

8. Sang H, HyeokáPark J (2010) "CdS or CdSe decorated $\mathrm{TiO}_{2}$ nanotube arrays from spray pyrolysis deposition: use in photoelectrochemical cells." Chemical communications 46: 2385-2387.

9. Kathalingam A, Kim MR, Chae YS, Rhee JK, Thanikaikarasan, et al. (2010) Study on electrodeposited CdSexTe1-x semiconducting thin films. J Alloys Compd 505: 758-761.

10. Luo J, Wei H, Huang Q, Zhao H, Yu R, et al. (2013) Highly efficient core-shell CulnS2-Mn doped CdS quantum dot sensitized solar cells, Chem. Commun 49: 3881.

11. Luo J, Wei H, Huang Q, Zhao H, Yu R, et al. (2014) Microwave assisted aqueous synthesis of core-shell CdSexTe1-x-CdS quantum dots for high performance sensitized solar cells. Chem. Commun 50: 3464.

12. David C, Kahn A (2003) "Electron energetics at surfaces and interfaces: concepts and experiments." Advanced Materials 15: 271-277.

13. Lee HJ, Yum JH, Leventis HC, Zakeeruddin SM, Haque SA, et al. (2008) CdSe quantum dot-sensitized solar cells exceeding efficiency $1 \%$ at full-sun intensity. The Journal of Physical Chemistry C 112: 11600-11608.

14. Jean D, Graetzel M, Kavan L, Moser J, Augustynski J (1985) "Highly efficien sensitization of titanium dioxide." Journal of the American Chemical Society 107: $2988-2990$.
15. Gruber DP, Meinhardt G, Papousek W (2005) Modelling the light absorption in organic photovoltaic devices. solar energy materials and solar cells 87: 215-223.

16. Sterbacka R, An CP, Jiang XM, Vardeny ZV (2000) Two-dimensional electronic excitations in self-assembled conjugated polymer nanocrystals. Science 287 : 839-842.

17. Hwang IW, Moses D, Heeger AJ (2008) Photoinduced carrier generation in P3HT/PCBM bulk heterojunction materials. J Phys Chem C 112: 4350-4354.

18. Offermans T, Meskers SCJ, Janssen RAJ (2003) Charge recombination in a poly (paraphenylene vinylene)-fullerene derivative composite film studied by transient, nonresonant, hole-burning spectroscopy. J Chem Phys 119: 1092410929.

19. Offermans $H$, van Hal A, Meskers SCJ, Koetse MM, Janssen RAJ (2005) Exciplex dynamics in a blend of pi-conjugated polymers with electron donating and accepting properties: (MDMO-PPV) and (PCNEPV). Phys. Rev. B 72: 045213.

20. De S, Pascher T, Maiti M, Jespersen KG, Kesti T, et al. (2007) Geminate charge recombination in alternating polyfluorene Copolymer/Fullerene blends. J Am Chem Soc 129: 8466-8472.

21. Marsh RA, Groves C, Greenham NC (2007) A microscopic model for the behavior of nanostructured organic photovoltaic devices. J Appl Phys 101 083509

22. Desmica-Frankovic D, Dubeek P, Buljan M, Furric K, Desnica UV, et al. (2005) Nucl. Instr. Meth. Phys. Res. B 238: 302.

23. Godovsky D, Chen L, Pettersson L, Ingana ĖO, Andersson MR, et al. (2000) Advanced Materials for optics and electronics. Adv Mater Opt Electron 10: 47-54.

24. Fengling Z, Perzon E, Wang X, Mammo W, Andersson MR, et al. (2005) "Polymer solar cells based on a low-bandgap fluorene copolymer and a fullerene derivative with photocurrent extended to $850 \mathrm{~nm}$." Advanced Functional Materials 15: 745-750.

25. Martijn L, Morana M, Brabec JC, WM Blom (2009) "Recombination-Limited Photocurrents in Low Bandgap Polymer/Fullerene Solar Cells." Advanced Functional Materials 19: 1106-1111.

26. Jang J, Seok-In N, Seok-Soon K, Tae-Woo L, Chung L, et al. (2009) "Three Dimensional Bulk Heterojunction Morphology for Achieving High Internal Quantum Efficiency in Polymer Solar Cells." Advanced Functional Materials 19: 2398-2406.

27. Yuan M, Lin $Y$ (2006) Model selection and estimation in regression with grouped variables. Journal of the Royal Statistical Society: Series B (Statistical Methodology) 68: 49-67.

28. Nogueira AF, Durrant JR, De Paoli MA (2001) Dye-sensitized nanocrystalline solar cells employing a polymer electrolyte. Advanced Materials 13: 826-826.

29. Jo JW, Kim Y, Ko MJ, Son HJ (2016) Development of intrinsically fullerenecompatible polymers: Strategy for developing high performance organic solar cells using a nonhalogenated solvent. Dyes and Pigments 132: 103-109.

30. Wang W, Zeng FL, Wang X, Tan MY (1996) A study of an oxovanadium (V) complex with a tridentate Schiff base ligand. Polyhedron 15: 1699-1703. 